\title{
VISIBILIDADE DO INDÍGENA EM SITUAÇÃO URBANA NAS MICRORREGIÕES DO ESTADO DO AMAZONAS A PARTIR DO CENSO DEMOGRÁFICO
}

\author{
MARCELO ROCHA RADICCHI ${ }^{1}$ \\ UFAM, BRASIL \\ https://orcid.org/0000-0003-2829-1439
}

\begin{abstract}
RESUMO: Este trabalho comparou o perfil socioeconômico e demográfico da população indígena residente em área urbana nas microrregiões do estado do Amazonas com nãoindígenas. Analisaram-se dados do Universo extraídos do SIDRA/IBGE, Censo Demográfico de 2010. Consideraram-se as treze microrregiões do estado. O Amazonas é um estado de maioria parda e urbana $(79,1 \%)$, com os indígenas perfazendo 4,8\% do total. Na situação urbana, em 11 das 13 microrregiões, a população indígena feminina é maior. As pirâmides demográficas indigenas apresentam base alargada, indicativa de uma população jovem. O percentual médio de alfabetização dos indigenas é o menor comparado com as demais categorias de cor/raça. Os indígenas são os mais frequentes na categoria "sem rendimento" em 6 microrregiões e se concentram na faixa de rendimento "até um salário mínimo". A situação socioeconômica desfavorável dos indígenas urbanos corrobora os resultados de outras investigações sobre demografia indígena. Sugere-se expandir as análises de modo a considerar, entre outros aspectos, dados acerca de pertencimento étnico específico, podendo ser realizado a partir do Banco Multidimensional de Estatísticas (BME) do IBGE.
\end{abstract}

PALAVRAS-CHAVE: Demografia, Características da população, População indígena, Fatores Socioeconômicos

ABSTRACT: This paper compares the socioeconomic and demographic profile of the indigenous population residing in the urban area in the micro-regions of the state of Amazonas with non-indigenous people. We analyzed the data from the Universe extracted from SIDRA/IBGE, 2010 Demographic Census. We considered all the thirteen microregions of the state. Amazonas is a majority urban (79.1\%) mixed color/race state, with indigenous people reaching $4.8 \%$ of the total. Considering the urban situation, in 11 of the 13 micro-regions, the female indigenous population is larger. The indigenous population demographic pyramids show a broad base, indicative of a young population. The average percentage of indigenous literacy is lower compared to the other color/race categories. Indigenous people are the most frequent in the "no income" category in 6 micro-regions and are concentrated in the income range "up to a minimum wage". The unfavorable socioeconomic situation of urban indigenous people corroborates the results of other investigations on indigenous demography. We suggest expanding the analyzes in order to consider, among other aspects, data on specific ethnic belonging, which can be carried out from the IBGE Multidimensional Statistics Bank (BME).

KEYWORDS: Demography, Population Characteristics, Indigenous Population, Socioeconomic Factors

\footnotetext{
${ }^{1}$ Doutor em Epidemiologia em Saúde Pública ENSP/FIOCRUZ. Professor Adjunto no Instituto de Ciências Sociais, Educação e Zootecnia do Campus Parintins da Universidade Federal do Amazonas. E-mail: radicchi@ufam.edu.br
} 


\section{Introdução}

O Censo Demográfico de 2010 no Brasil trouxe diversas inovações metodológicas, de conteúdo temático e tecnológicas, respeitando princípios internacionais em sua elaboração e condução² (IBGE, 2010a). Constituiu iniciativa integrada no esforço conjunto empreendido pelos países latino-americanos de aumento da visibilidade estatística dos povos indígenas (DEL POPOLO \& SCHKOLNIK, 2013). Resultados importantes foram divulgados, incluindo a publicação de um volume especial dedicado à análise das informações coletadas para a população indígena no Brasil (IBGE, 2012).

O Censo Demográfico de 2010 conduzido pelo Instituto Brasileiro de Geografia e Estatística (IBGE) trouxe inovações importantes na caracterização da população indígena, coletando informação sobre a etnia e língua falada, além de identificar a população residente nas terras indígenas e fora delas (IBGE, 2012). Auxiliou também na promoção da "visibilidade" sociodemográfica desta parcela da população nas estatísticas nacionais (SANTOS \& TEIXEIRA, 2011), auxiliando na superação do conhecido quadro de insuficiência de informações demográficas para estas populações (PAGLIARO et al., 2005).

No Brasil a presença indígena concentra-se na situação de domicílio rural, embora 36,2\% (324.834 indivíduos) destes residam em centros urbanos (IBGE, 2012). O Amazonas é o estado brasileiro com a maior população indígena considerando ambas situações de domicílio (168.680 indivíduos), sendo, entretanto, o terceiro em termos de população indígena urbana, atrás de São Paulo e Bahia (IBGE, 2012). O estado do Amazonas abriga o município brasileiro com maior população indígena urbana (IBGE, 2012), São Gabriel da Cachoeira (localizado na microrregião do Rio Negro), sendo também o estado com maior área absoluta de terra indígena demarcada (ISA, 2015).

Os indígenas em situação urbana têm sido estudados no estado do Amazonas sob a perspectiva socioeconômica e demográfica (FÍGOLI, 1985; MAINBOURG et al., 2002, 2006, 2008; TEIXEIRA, 2005; FÍGOLI \& FAZITO, 2006; TEIXEIRA et al., 2009). No contexto nacional, quando são comparados com as demais categorias de cor/raça, os indígenas urbanos apresentam prejuízo nos indicadores socioeconômicos, seja em escolaridade, alfabetização, ocupação, rendimento e condições do domicílio, em relação à categoria de cor/raça branca (IBGE, 2005). Tal situação parece válida também para o estado do Amazonas (MAINBOURG et al., 2006, 2008).

As análises sobre a população indígena divulgadas pelo IBGE com dados do Censo Demográfico 2010 (IBGE, 2012) possuem ampla abrangência, porém pouca profundidade regional, tratando basicamente, das regiões e as Unidades da Federação (IBGE, 2012). Unidades de análise mais pormenorizadas (macro, meso e microrregiões, municípios) não

\footnotetext{
${ }^{2}$ Pode-se citar a participação do Brasil na aprovação do documento final (Principles and recommendations for population and housing censuses: revision 2) da $37^{\mathrm{a}}$ sessão da Comissão de Estatística das Nações Unidas em 2008. O referido documento abordava os tópicos a serem investigados nos censos de população e de habitação (IBGE, 2010b) para o período de 2010 a 2014.
} 
foram divulgadas. Uma análise mais localizada, considerando unidades territoriais dentro de um estado, torna possível a visualização das desigualdades socioeconômicas entre os grupos populacionais, no caso, os indígenas e as demais categorias de cor/raça no território. Há uma preocupação na demografia indígena com a promoção da "visibilidade estatística" para esta população, sendo entendida como elemento fundamental na implementação de seus direitos fundamentais (PAGLIARO et al., 2005; CEPAL, 2014).

Busca-se neste estudo descrever o perfil socioeconômico e demográfico da população indígena residente em área urbana nas microrregiões do estado do Amazonas, a partir de dados do Censo Demográfico 2010, comparando-se com os não-indígenas.

\section{Materiais e métodos}

Analisaram-se dados do Universo do Censo Demográfico 2010 (IBGE, 2011 ) extraídos por meio da plataforma do SIDRA (Sistema Integrado de Recuperação Automática) do IBGE, contemplando a situação de domicílio urbana nas treze microrregiões do estado do Amazonas. Dados do Universo dizem respeito ao conjunto de dados "formado pela junção dos registros de todos os domicílios investigados pelo questionário básico e, também, pelo questionário da amostra, considerando apenas as variáveis comuns aos dois tipos de questionário" (IBGE, 2013, p. 561). O SIDRA/IBGE seria a ferramenta criada e mantida pelo IBGE que viabiliza o armazenamento de tabelas de dados agregados coletados pelo IBGE a partir de diversas pesquisas (Censo Demográfico 2010 é uma delas), possibilitando ao pesquisador interessado a realização de novos cruzamentos de dados; sendo de acesso livre via website próprio ${ }^{3}$ (IBGE, 2013).

Quanto à classificação da população em situação do domicílio, o critério considerado como "urbano" pelo IBGE corresponde à população que reside em "áreas, urbanizadas ou não, internas ao perímetro urbano das cidades (sedes municipais) ou vilas (sedes distritais) ou as áreas urbanas isoladas, conforme definido por Lei Municipal vigente em 31 de julho de 2010" (IBGE, 2010a, p. 26). Contemplando a possibilidade de a área urbana de uma cidade ou vila não estar definida em regulamentação específica (ex: plano diretor municipal) - fato bastante plausível de ocorrência no contexto do Amazonas, dada sua extensão geográfica e as características demográficas e de povoamento próprias, historicamente construídas - há a previsão ainda da definição do perímetro das áreas urbanas ocorrer em acordo do IBGE com a prefeitura local (IBGE, 2010a). Áreas rurais seria aquelas situadas fora destes critérios (IBGE, 2010a).

Conforme definição, microrregiões são entendidas como "um conjunto de municípios, contíguos e contidos na mesma Unidade da Federação, definidos com base em características do quadro natural, da organização da produção e de sua integração" (IBGE, 2010a, p. 22),

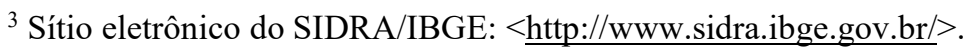


enquanto mesorregiões, no âmbito da divisão territorial proposta pelo IBGE, seria o conjunto de microrregiões (IBGE, 2010a). O entendimento em ambos conceitos é o de territórios contíguos na mesma Unidade da Federação, considerando aspectos naturais, sociais, rede de comunicação e lugares determinados.

No âmbito da pesquisa, optou-se pela análise das microrregiões pelo motivo de manterem a nomenclatura vinculada a referências geográficas importantes (calha do rio principal onde a microrregião se localiza ou ao município de maior influência político-econômica na microrregião), e de possibilitarem quantitativamente as análises comparativas entre os indígenas e as demais a categoria de cor/raça.

As microrregiões revelaram ser o nível mais adequado de análise: mais aprofundada em contraposição à análise por mesorregiões (estas últimas não fazem referência ao território e às calhas de rios importantes), e mais adequada do ponto de vista comparativo, caso fosse realizada considerando os municípios, tendo em vista existirem diversos com baixa população indígena urbana. Dados do Universo do Censo de 2010 (IBGE, 2011) extraídos do SIDRA/IBGE ilustram a situação da população indígena urbana nos municípios no estado do Amazonas: a mediana considerando os 62 municípios do estado é de 127 indivíduos, o terceiro quartil (75\% das observações) retorna 337 indivíduos e somente 12 dos 62 municípios têm população indígena urbana acima dos 500 indivíduos. Tal realidade dificultaria as análises comparativas que considerassem estratificações (por sexo, idade, categorias de renda, etc.) na população de interesse.

De maneira a possibilitar as comparações entre as unidades analisadas, optou-se pela realização da análise comparativa somente para as microrregiões que apresentavam um mínimo populacional de 500 indígenas urbanos. Sete das treze microrregiões cumpriram o critério e foram consideradas nas análises comparativas de cor/raça: Alto Solimões, Boca do Acre, Madeira, Manaus, Parintins, Purus e Rio Negro. As sete microrregiões contabilizaram $95,5 \%$ do total de indígenas em situação urbana no estado (34.302 indivíduos). Por totalizar menos de $1 \%$ da população total, não foram contabilizados os dados relativos a categoria de cor/raça amarela nas análises comparativas.

As análises do estudo iniciaram pela descrição das características gerais da população (urbana, rural e total), aprofundando-se, então, para a situação urbana. Calcularam-se as proporções para as variáveis de cor/raça em cada microrregião em relação aos itens analisados: distribuição conforme situação de domicílio, distribuição etária e por sexo, alfabetização, faixa de rendimento e características do entorno do domicílio. Procedeu-se então à comparação entre as proporções apresentadas pelas categorias de cor/raça.

As variáveis aqui analisadas, conforme definição no Censo Demográfico 2010, serão esclarecidas. No questionário básico, "alfabetização" foi considerada para todas as pessoas de 5 ou mais anos de idade que preenchiam o quesito "saber ler e escrever" (IBGE, 2010b), mais detalhadamente, "a pessoa capaz de ler e escrever um bilhete simples no idioma que conhecesse" (IBGE, 2011, p. 27). "Faixa de 
rendimento" utilizou classes de salário mínimo, equivalente ao valor do mês de referência, ou, R\$510,00 (quinhentos e dez reais) (IBGE, 2011). As classes de rendimento aqui analisadas dizem respeito ao rendimento nominal mensal domiciliar per capita, ou seja, a classe de valor correspondente à divisão do rendimento mensal domiciliar pelo número de moradores do domicílio particular, excluindo-se aqueles cuja condição no domicílio fosse pensionista, empregado doméstico ou parente do empregado doméstico (IBGE, 2011).

As características do entorno dos domicílios referem-se apenas àqueles localizados em áreas com ordenamento urbano regular (IBGE, 2010a) e foram respondidas pelo supervisor responsável por um grupo de recenseadores de campo que trabalharam junto ao Censo demográfico 2010 (IBGE, 2013). Estes supervisores respondiam conforme sua percepção sobre "existência de calçamento e iluminação pública na rua visitada, se há esgoto a céu aberto, lixão ou depósito de lixo próximo aos respectivos domicílios" entre outros quesitos (IBGE, 2013, p. 41).

\section{Resultados}

Considerando a população urbana e rural (3.483.979 indivíduos), a categoria de cor/raça mais numerosa é a dos pardos $(68,9 \%)$, seguida pelos brancos $(21,2 \%)$, indígenas $(4,8)$, pretos $(4,1 \%)$ e amarelos $(0,9 \%)$. A microrregião mais populosa é Manaus $(58,5 \%$ da população total do estado), seguida por Parintins e Alto Solimões.

Tabela 1: População total no Amazonas por microrregiões conforme categorias de cor/raça segundo o Censo Demográfico 2010. Amazonas

\begin{tabular}{l|ccccc|c|c}
\hline Microrregião & Branca (\%) & Preta (\%) & $\begin{array}{c}\text { Amarela } \\
(\%)\end{array}$ & Parda (\%) & Indígena (\%) & Total (\%) \\
\hline Alto Solimões & $20565(9,2)$ & $6356(2,8)$ & $1048(0,5)$ & $134224(59,9)$ & $61901(27,2)$ & $224094(100,0)$ \\
Boca do Acre & $11123(22,8)$ & $3243(6,6)$ & $350(0,7)$ & $31161(63,9)$ & $2921(6,0)$ & $48798(100,0)$ \\
Coari & $20543(13,5)$ & $7298(4,8)$ & $1200(0,8)$ & $121680(80,0)$ & $1441(0,9)$ & $152162(100,0)$ \\
Itacoatiara & $25756(16,9)$ & $4392(2,9)$ & $934(0,6)$ & $119971(78,9)$ & $973(0,6)$ & $152026(100,0)$ \\
Japurá & $3056(12,3)$ & $1137(4,6)$ & $97(0,4)$ & $18067(72,7)$ & $2497(10,0)$ & $24854(100,0)$ \\
Juruá & $29901(23,4)$ & $6905(5,4)$ & $949(0,7)$ & $84583(66,2)$ & $5507(4,3)$ & $127845(100,0)$ \\
Madeira & $33950(20,5)$ & $7568(4,6)$ & $1291(0,8)$ & $112452(67,9)$ & $10402(6,3)$ & $165663(100,0)$ \\
Manaus & $521037(25,5)$ & $87088(4,3)$ & $22850(1,1)$ & $1395192(68,4)$ & $13365(0,7)$ & $2039532(100,0)$ \\
Parintins & $28151(11,6)$ & $5441(2,2)$ & $708(0,3)$ & $196239(80,9)$ & $12141(5,0)$ & $242680(100,0)$ \\
Purus & $14473(20,8)$ & $2504(3,6)$ & $212(0,3)$ & $47013(67,6)$ & $5314(7,6)$ & $69516(100,0)$ \\
Rio Negro & $7336(7,6)$ & $3183(3,3)$ & $1001(1,0)$ & $36098(37,4)$ & $48865(50,6)$ & $96483(100,0)$ \\
Rio Preto da & $11095(21,0)$ & $4741(9,0)$ & $762(1,4)$ & $35577(67,3)$ & $719(1,4)$ & $52894(100,0)$ \\
Eva & $13079(15,0)$ & $3892(4,5)$ & $371(0,4)$ & $67456(77,2)$ & $2634(3,0)$ & $87432(100,0)$ \\
Tefé & 740065 & 143748 & 31773 & 2399713 & 168680 & 3483979 \\
\hline \multicolumn{1}{c}{ TOTAL } & $(21,2)$ & $(4,1)$ & $(0,9)$ & $(68,9)$ & $(4,8)$ & $(100,0)$ \\
\hline
\end{tabular}

Fonte: SIDRA/IBGE. Tabela 3145. Censo Demográfico 2010. Resultados do Universo.

A figura 1 localiza as microrregiões do estado do Amazonas, apresentando o percentual da população indígena (urbana e rural) em 
cada uma das microrregiões (conforme Tabela 1), considerando a população total em cada microrregião.

Figura 1: Microrregiões do estado do Amazonas com o respectivo percentual da população indígena.

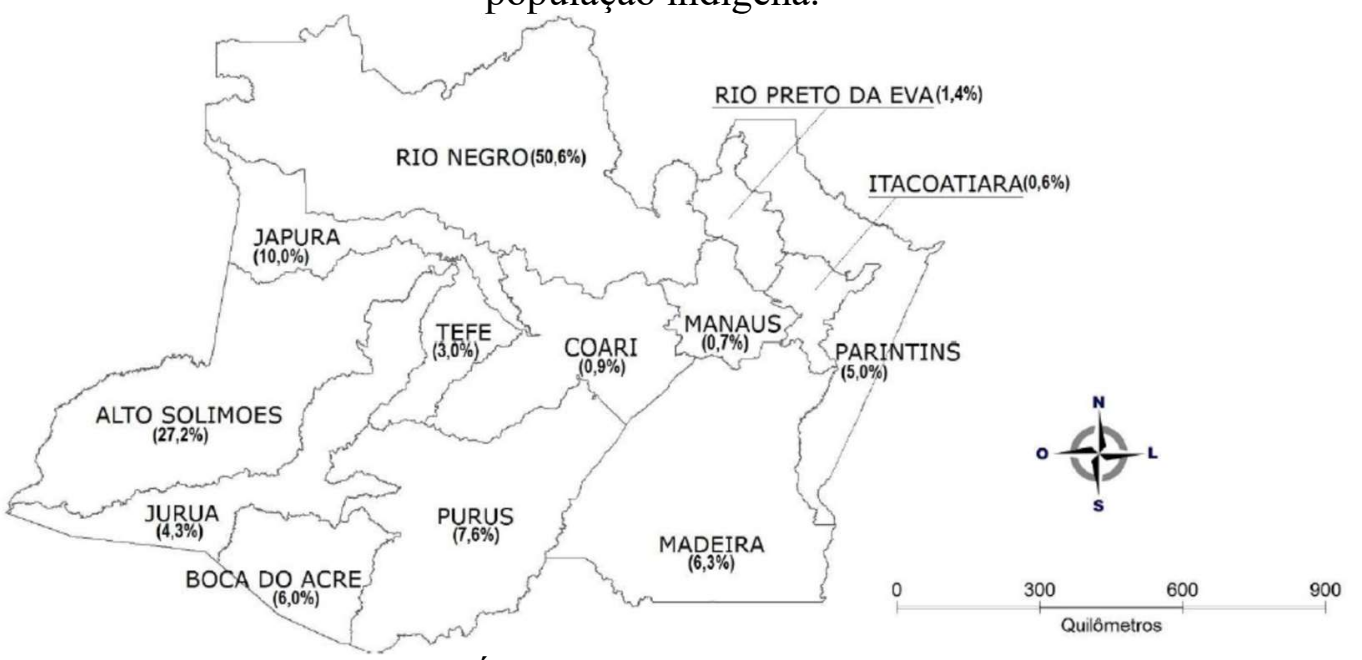

Fonte: IBGE. Índice de malhas digitais. Amazonas. 2010.

Se for considerada a população indígena em número absoluto, as três microrregiões com maior população são: Alto Solimões, Rio Negro e Manaus. Quando consideramos as com os maiores percentuais de população indígena em relação à população total, temos Rio Negro $(50,6 \%)$, Alto Solimões $(27,6 \%)$ e Japurá $(10 \%)$, sendo que esta última microrregião é a que possui menor população total (24.854 indivíduos).

Tabela 2: População urbana e rural por microrregiões conforme categorias de cor/raça segundo o Censo Demográfico 2010. Amazonas.

\begin{tabular}{|c|c|c|c|c|c|c|c|c|c|c|c|c|}
\hline \multirow[b]{2}{*}{$\begin{array}{l}\text { Micror } \\
\text { região }\end{array}$} & \multicolumn{6}{|c|}{ URBANO } & \multicolumn{6}{|c|}{ RURAL } \\
\hline & $\begin{array}{c}\text { Bran } \\
\text { ca }(\%)\end{array}$ & $\begin{array}{c}\text { Preta } \\
(\%)\end{array}$ & $\begin{array}{l}\text { Ama } \\
\text { rela } \\
(\%) \\
\end{array}$ & $\begin{array}{c}\text { Parda } \\
(\%)\end{array}$ & $\begin{array}{l}\text { Indí } \\
\text { gena } \\
(\%)\end{array}$ & $\begin{array}{c}\text { Total } \\
(\%)\end{array}$ & $\begin{array}{c}\text { Bran } \\
\text { ca (\%) }\end{array}$ & $\begin{array}{c}\text { Preta } \\
(\%)\end{array}$ & $\begin{array}{l}\text { Ama } \\
\text { rela } \\
(\%)\end{array}$ & $\begin{array}{c}\text { Parda } \\
(\%)\end{array}$ & $\begin{array}{l}\text { Indí } \\
\text { gena } \\
(\%)\end{array}$ & $\begin{array}{c}\text { Total } \\
(\%)\end{array}$ \\
\hline $\begin{array}{l}\text { Alto } \\
\text { Solimões }\end{array}$ & $\begin{array}{l}17462 \\
(13,4)\end{array}$ & $\begin{array}{l}3675 \\
(2,8)\end{array}$ & $\begin{array}{c}875 \\
(0,7)\end{array}$ & $\begin{array}{c}100692 \\
(77,4)\end{array}$ & $\begin{array}{l}7418 \\
(5,7)\end{array}$ & $\begin{array}{l}130122 \\
(100,0)\end{array}$ & $\begin{array}{l}3103 \\
(3,3)\end{array}$ & $\begin{array}{l}2681 \\
(2,9)\end{array}$ & $\begin{array}{c}173 \\
(0,2)\end{array}$ & $\begin{array}{l}33532 \\
(35,7)\end{array}$ & $\begin{array}{l}54483 \\
(58,0)\end{array}$ & $\begin{array}{r}93972 \\
(100,0)\end{array}$ \\
\hline $\begin{array}{l}\text { Boca do } \\
\text { Acre }\end{array}$ & $\begin{array}{l}8122 \\
(28,4)\end{array}$ & $\begin{array}{l}1603 \\
(5,6)\end{array}$ & $\begin{array}{l}253 \\
(0,9)\end{array}$ & $\begin{array}{l}18119 \\
(63,3)\end{array}$ & $\begin{array}{l}515 \\
(1,8)\end{array}$ & $\begin{array}{l}28612 \\
(100,0)\end{array}$ & $\begin{array}{c}3001 \\
(14,9)\end{array}$ & $\begin{array}{l}1640 \\
(8,1)\end{array}$ & $\begin{array}{c}97 \\
(0,5)\end{array}$ & $\begin{array}{l}13042 \\
(64,6)\end{array}$ & $\begin{array}{l}2406 \\
(11.9)\end{array}$ & $\begin{array}{l}20186 \\
(100,0)\end{array}$ \\
\hline Coari & $\begin{array}{l}15040 \\
(16,3)\end{array}$ & $\begin{array}{l}4297 \\
(4,6)\end{array}$ & $\begin{array}{l}805 \\
(0,9)\end{array}$ & $\begin{array}{l}72159 \\
(78,0)\end{array}$ & $\begin{array}{l}247 \\
(0,3)\end{array}$ & $\begin{array}{l}92548 \\
(100,0)\end{array}$ & $\begin{array}{l}5503 \\
(9,2)\end{array}$ & $\begin{array}{l}3001 \\
(5,0)\end{array}$ & $\begin{array}{c}395 \\
(0,7)\end{array}$ & $\begin{array}{l}49521 \\
(83,1)\end{array}$ & $\begin{array}{l}1194 \\
(2,0)\end{array}$ & $\begin{array}{c}59614 \\
(100,0)\end{array}$ \\
\hline Itacoatiara & $\begin{array}{l}18611 \\
(20,1)\end{array}$ & $\begin{array}{l}2712 \\
(2,9)\end{array}$ & $\begin{array}{c}512 \\
(0,6)\end{array}$ & $\begin{array}{l}70397 \\
(75,9)\end{array}$ & $\begin{array}{l}478 \\
(0,5)\end{array}$ & $\begin{array}{l}92710 \\
(100,0)\end{array}$ & $\begin{array}{l}7145 \\
(12,0)\end{array}$ & $\begin{array}{l}1680 \\
(2,8)\end{array}$ & $\begin{array}{l}422 \\
(0,7)\end{array}$ & $\begin{array}{l}49574 \\
(83,6)\end{array}$ & $\begin{array}{l}495 \\
(0,8)\end{array}$ & $\begin{array}{r}59316 \\
(100,0)\end{array}$ \\
\hline Japurá & $\begin{array}{c}1818 \\
(15,1)\end{array}$ & $\begin{array}{c}697 \\
(5,8)\end{array}$ & $\begin{array}{c}78 \\
(0,6)\end{array}$ & $\begin{array}{l}9419 \\
(78,2)\end{array}$ & $\begin{array}{c}39 \\
(0,3)\end{array}$ & $\begin{array}{l}12051 \\
(100,0)\end{array}$ & $\begin{array}{l}1238 \\
(9,7)\end{array}$ & $\begin{array}{l}440 \\
(3,4)\end{array}$ & $\begin{array}{c}19 \\
(0,1)\end{array}$ & $\begin{array}{l}8648 \\
(67,5)\end{array}$ & $\begin{array}{l}2458 \\
(19,2)\end{array}$ & $\begin{array}{l}12803 \\
(100,0)\end{array}$ \\
\hline Juruá & $\begin{array}{l}20560 \\
(25,8)\end{array}$ & $\begin{array}{l}3681 \\
(4,6)\end{array}$ & $\begin{array}{c}731 \\
(0,9)\end{array}$ & $\begin{array}{l}54369 \\
(68,3)\end{array}$ & $\begin{array}{l}205 \\
(0,3)\end{array}$ & $\begin{array}{l}79546 \\
(100,0)\end{array}$ & $\begin{array}{l}9341 \\
(19,3)\end{array}$ & $\begin{array}{l}3224 \\
(6,7)\end{array}$ & $\begin{array}{l}218 \\
(0,5)\end{array}$ & $\begin{array}{l}30214 \\
(62,6)\end{array}$ & $\begin{array}{l}5302 \\
(11,0)\end{array}$ & $\begin{array}{r}48299 \\
(100,0)\end{array}$ \\
\hline Madeira & $\begin{array}{l}21817 \\
(24,3)\end{array}$ & $\begin{array}{l}4278 \\
(4,8)\end{array}$ & $\begin{array}{c}794 \\
(0,9)\end{array}$ & $\begin{array}{l}62382 \\
(69,3)\end{array}$ & $\begin{array}{c}682 \\
(0,8)\end{array}$ & $\begin{array}{l}89953 \\
(100,0)\end{array}$ & $\begin{array}{l}12133 \\
(16,0)\end{array}$ & $\begin{array}{l}3290 \\
(4,3)\end{array}$ & $\begin{array}{c}497 \\
(0,7)\end{array}$ & $\begin{array}{l}50070 \\
(66,1)\end{array}$ & $\begin{array}{l}9720 \\
(12,8)\end{array}$ & $\begin{array}{l}75710 \\
(100,0)\end{array}$ \\
\hline Manaus & $\begin{array}{c}502037 \\
(26,2)\end{array}$ & $\begin{array}{c}80350 \\
(4,2)\end{array}$ & $\begin{array}{c}21657 \\
(1,1)\end{array}$ & $\begin{array}{c}1302354 \\
(68,1)\end{array}$ & $\begin{array}{l}7024 \\
(0,4)\end{array}$ & $\begin{array}{c}1913422 \\
(100,0)\end{array}$ & $\begin{array}{l}19000 \\
(15,1)\end{array}$ & $\begin{array}{l}6738 \\
(5,3)\end{array}$ & $\begin{array}{l}1193 \\
(0,9)\end{array}$ & $\begin{array}{l}92838 \\
(73,6)\end{array}$ & $\begin{array}{l}6341 \\
(5,0)\end{array}$ & $\begin{array}{l}126110 \\
(100,0)\end{array}$ \\
\hline Parintins & $\begin{array}{l}21794 \\
(15,7)\end{array}$ & $\begin{array}{l}3405 \\
(2,5)\end{array}$ & $\begin{array}{c}547 \\
(0,4)\end{array}$ & $\begin{array}{c}111733 \\
(80,7)\end{array}$ & $\begin{array}{l}1011 \\
(0,7)\end{array}$ & $\begin{array}{l}138490 \\
(100,0)\end{array}$ & $\begin{array}{l}6357 \\
(6,1)\end{array}$ & $\begin{array}{l}2036 \\
(2,0)\end{array}$ & $\begin{array}{c}161 \\
(0,2)\end{array}$ & $\begin{array}{l}84506 \\
(81,1)\end{array}$ & $\begin{array}{l}11130 \\
(10,7)\end{array}$ & $\begin{array}{l}104190 \\
(100,0)\end{array}$ \\
\hline Purus & $\begin{array}{l}10067 \\
(24,3)\end{array}$ & $\begin{array}{l}1804 \\
(4,3)\end{array}$ & $\begin{array}{c}196 \\
(0,5)\end{array}$ & $\begin{array}{l}28067 \\
(67,6)\end{array}$ & $\begin{array}{l}1373 \\
(3,3)\end{array}$ & $\begin{array}{l}41507 \\
(100,0)\end{array}$ & $\begin{array}{l}4406 \\
(15,7)\end{array}$ & $\begin{array}{c}700 \\
(2,5)\end{array}$ & $\begin{array}{c}16 \\
(0,1)\end{array}$ & $\begin{array}{l}18946 \\
(67,6)\end{array}$ & $\begin{array}{l}3941 \\
(14,1)\end{array}$ & $\begin{array}{l}28009 \\
(100,0)\end{array}$ \\
\hline Rio Negro & $\begin{array}{c}6042 \\
(13,0)\end{array}$ & $\begin{array}{l}2018 \\
(4,3)\end{array}$ & $\begin{array}{c}343 \\
(0,7)\end{array}$ & $\begin{array}{l}23417 \\
(50,3)\end{array}$ & $\begin{array}{l}14746 \\
(31,7)\end{array}$ & $\begin{array}{l}46566 \\
(100,0)\end{array}$ & $\begin{array}{l}1294 \\
(2,6)\end{array}$ & $\begin{array}{l}1165 \\
(2,3)\end{array}$ & $\begin{array}{c}658 \\
(1,3)\end{array}$ & $\begin{array}{l}12681 \\
(25,4)\end{array}$ & $\begin{array}{l}34119 \\
(68,4)\end{array}$ & $\begin{array}{l}49917 \\
(100,0)\end{array}$ \\
\hline $\begin{array}{l}\text { Rio Preto } \\
\text { da Eva }\end{array}$ & $\begin{array}{l}5756 \\
(22,8)\end{array}$ & $\begin{array}{l}2322 \\
(9,2)\end{array}$ & $\begin{array}{c}529 \\
(2,1)\end{array}$ & $\begin{array}{l}16454 \\
(65,3)\end{array}$ & $\begin{array}{c}145 \\
(0,6)\end{array}$ & $\begin{array}{l}25206 \\
(100,0)\end{array}$ & $\begin{array}{c}5339 \\
(19,3)\end{array}$ & $\begin{array}{l}2419 \\
(8,7)\end{array}$ & $\begin{array}{c}233 \\
(0,8)\end{array}$ & $\begin{array}{l}19123 \\
(69,1)\end{array}$ & $\begin{array}{c}574 \\
(2,1)\end{array}$ & $\begin{array}{l}27688 \\
(100,0)\end{array}$ \\
\hline Tefé & $\begin{array}{l}11018 \\
(17,0)\end{array}$ & $\begin{array}{l}2212 \\
(3,4)\end{array}$ & $\begin{array}{l}298 \\
(0,5)\end{array}$ & $\begin{array}{l}50804 \\
(78,5)\end{array}$ & $\begin{array}{l}419 \\
(0,6)\end{array}$ & $\begin{array}{c}64751 \\
(100,0)\end{array}$ & $\begin{array}{l}2061 \\
(9,1)\end{array}$ & $\begin{array}{l}1680 \\
(7,4)\end{array}$ & $\begin{array}{c}73 \\
(0,3)\end{array}$ & $\begin{array}{l}16652 \\
(73,4)\end{array}$ & $\begin{array}{l}2215 \\
(9,8)\end{array}$ & $\begin{array}{l}22681 \\
(100,0)\end{array}$ \\
\hline TOTAL & $\begin{array}{c}660144 \\
(24,0)\end{array}$ & $\begin{array}{c}113054 \\
(4,1)\end{array}$ & $\begin{array}{c}27618 \\
(1,0)\end{array}$ & $\begin{array}{c}1920366 \\
(69,7)\end{array}$ & $\begin{array}{c}34302 \\
(1,2)\end{array}$ & $\begin{array}{c}2755484 \\
(100,0)\end{array}$ & $\begin{array}{l}79921 \\
(11,0)\end{array}$ & $\begin{array}{c}30694 \\
(4,2)\end{array}$ & $\begin{array}{l}4155 \\
(0,6)\end{array}$ & $\begin{array}{c}479347 \\
(65,8)\end{array}$ & $\begin{array}{c}134378 \\
(18,4)\end{array}$ & $\begin{array}{l}728495 \\
(100,0)\end{array}$ \\
\hline
\end{tabular}

Fonte: SIDRA/IBGE. Tabela 3145. Censo Demográfico 2010. Resultados do Universo. 
A maior parcela da população do Amazonas é urbana $(79,1 \%)$. A microrregião de Manaus sozinha contabiliza pouco mais de 1,9 milhão de indivíduos do total de 2.755.484 em situação urbana.

Considerando somente a população urbana, os indígenas constituem $1,2 \%$ desta, sendo mais presentes somente que os amarelos (1,0\%). Quando se considera a área rural, os indígenas são a segunda categoria de cor/raça mais populosa $(18,4 \%)$, atrás dos pardos $(65,8 \%)$.

Para a população indígena urbana em cada microrregião, registra-se a maior presença no Rio Negro (31,7\% da população). Com exceção das microrregiões do Rio Negro, Alto Solimões, Purus e Boca do Acre, a presença indígena em situação urbana corresponde a menos de $1 \%$ da população. Em número absoluto, as três microrregiões com maiores populações de indígenas urbanas são Rio Negro, Alto Solimões e Manaus. Estas três microrregiões juntas contabilizam $85,1 \%$ desta população e serão analisadas com especial atenção, dada a relevância em termos quantitativos.

A população das sete microrregiões investigadas (Alto Solimões, Boca do Acre, Madeira, Manaus, Parintins, Purus e Rio Negro) equivale a 95,5\% (32.769) do total da população indígena em situação urbana do estado (34.302 indivíduos).

Tabela 3: População indígena nas microrregiões conforme situação de domicílio e sexo segundo o Censo Demográfico 2010. Amazonas.

\begin{tabular}{|c|c|c|c|c|c|c|}
\hline \multirow{2}{*}{ Microrregião } & \multicolumn{3}{|c|}{ URBANO } & \multicolumn{3}{|c|}{ RURAL } \\
\hline & Masculino (\%) & $\begin{array}{c}\text { Feminino } \\
(\%)\end{array}$ & Total $(\%)$ & Masculino (\%) & $\begin{array}{c}\text { Feminino } \\
(\%)\end{array}$ & Total $(\%)$ \\
\hline Alto Solimões & $3853(51,9)$ & $3565(48,1)$ & $7418(100,0)$ & $28386(52,1)$ & $26097(47,9)$ & $54483(100,0)$ \\
\hline Boca do Acre & $243(47,2)$ & $272(52,8)$ & $515(100,0)$ & $1247(51,8)$ & $1159(48,2)$ & $2406(100,0)$ \\
\hline Coari & $127(51,4)$ & $120(48,6)$ & $247(100,0)$ & $648(54,3)$ & $546(45,7)$ & $1194(100,0)$ \\
\hline Itacoatiara & $244(51,0)$ & $234(49,0)$ & $478(100,0)$ & $295(59,6)$ & $200(40,4)$ & $495(100,0)$ \\
\hline Japurá & $14(35,9)$ & $25(64,1)$ & $39(100,0)$ & $1287(52,4)$ & $1171(47,6)$ & $2458(100,0)$ \\
\hline Juruá & $96(46,8)$ & $109(53,2)$ & $205(100,0)$ & $2786(52,5)$ & $2516(47,5)$ & $5302(100,0)$ \\
\hline Madeira & $333(48,8)$ & $349(51,2)$ & $682(100,0)$ & $5212(53,6)$ & $4508(46,4)$ & $9720(100,0)$ \\
\hline Manaus & $3433(48,9)$ & $3591(51,1)$ & $7024(100,0)$ & $3363(53,0)$ & $2978(47,0)$ & $6341(100,0)$ \\
\hline Parintins & $514(50,8)$ & $497(49,2)$ & $1011(100,0)$ & $5689(51,1)$ & $5441(48,9)$ & $11130(100,0)$ \\
\hline Purus & $717(52,2)$ & $656(47,8)$ & $1373(100,0)$ & $2047(51,9)$ & $1894(48,1)$ & $3941(100,0)$ \\
\hline Rio Negro & $7209(48,9)$ & $7537(51,1)$ & $14746(100,0)$ & $17782(52,1)$ & $16337(47,9)$ & $34119(100,0)$ \\
\hline Rio Preto da Eva & $77(53,1)$ & $68(46,9)$ & $145(100,0)$ & $281(49,0)$ & $293(51,0)$ & $574(100,0)$ \\
\hline Tefé & $214(51,1)$ & $205(48,9)$ & $419(100,0)$ & $1202(54,3)$ & $1013(45,7)$ & $2215(100,0)$ \\
\hline TOTAL & $\begin{array}{l}17074 \\
(49,8)\end{array}$ & $\begin{array}{l}17228 \\
(50,2) \\
\end{array}$ & $\begin{array}{c}34302 \\
(100,0)\end{array}$ & $\begin{array}{l}70225 \\
(52,3) \\
\end{array}$ & $\begin{array}{l}64153 \\
(47,7) \\
\end{array}$ & $\begin{array}{l}134378 \\
(100,0) \\
\end{array}$ \\
\hline
\end{tabular}

Fonte: SIDRA/IBGE. Tabela 3145. Censo Demográfico 2010. Resultados do Universo.

Observam-se mais mulheres indígenas na situação urbana $(50,2 \%)$ que homens indígenas (49,8\%). Em 6 das 13 microrregiões, esta observação é verdadeira, embora seja pequena a diferença entre homens e mulheres.

Para a situação rural, observa-se maior diferença entre homens e mulheres indígenas, havendo maior presença dos primeiros nesta situação de domicílio (52,3\% contra 47,7\% para as mulheres). Somente na microrregião de Rio Preto da Eva os homens indígenas não contabilizam o maior percentual da população rural, sendo a microrregião com a segunda menor população indígena rural. Das 13 microrregiões, somente Manaus possui mais indígenas em situação urbana que em rural. 
Espaço Ameríndio

Figura 2: Pirâmides etárias de indígenas e não-indígenas* segundo situação de domicílio nas microrregiões analisadas** segundo o Censo Demográfico 2010.

Amazonas.

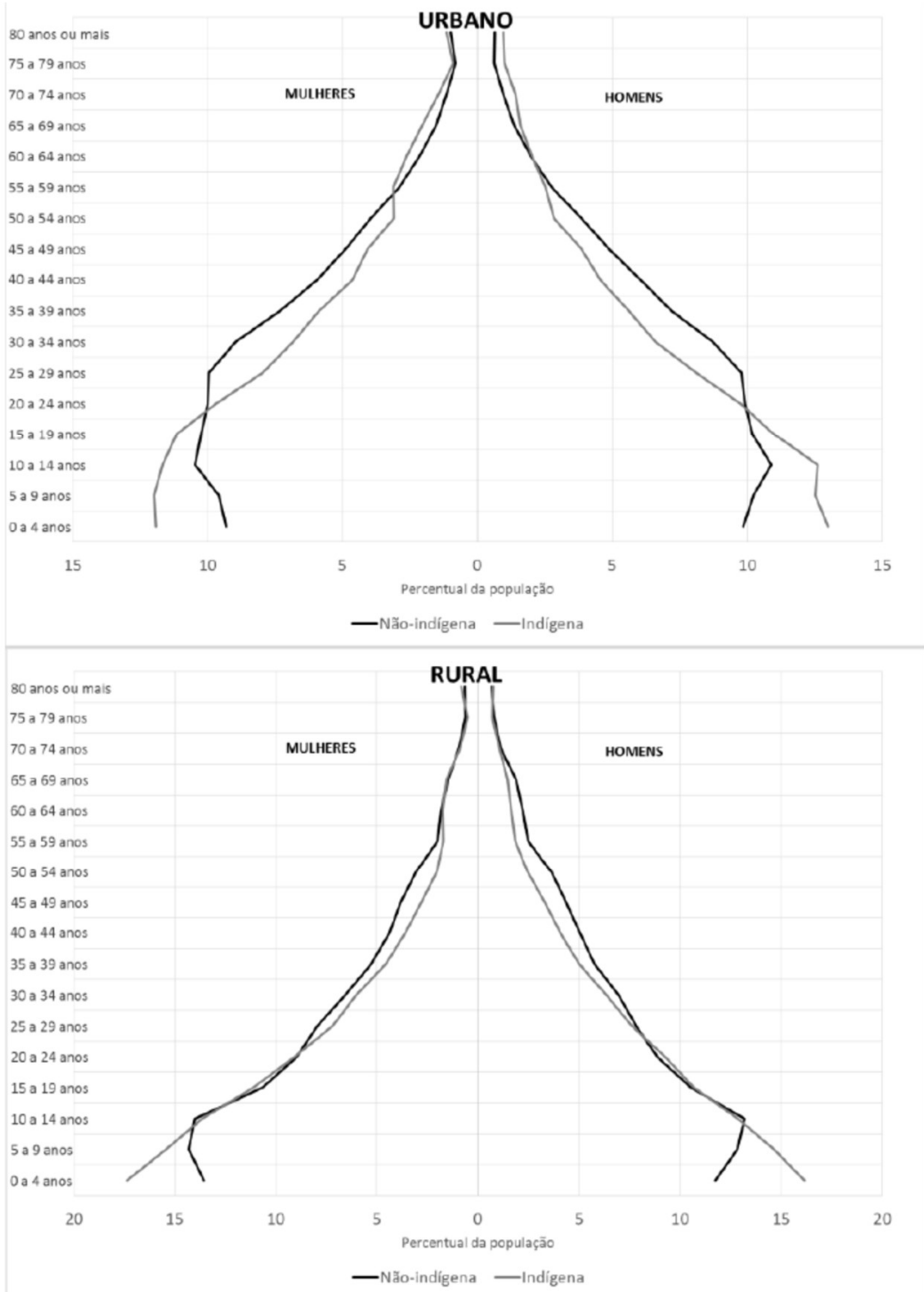

Fonte: SIDRA/IBGE. Tabela 3175. Censo Demográfico 2010. Resultados do Universo.

* Não-indígena inclui as categorias branca, preta, amarela e parda.

** Microrregiões: Alto Solimões, Boca do Acre, Madeira, Manaus, Parintins, Purus, Rio Negro.

Tanto na situação urbana quanto na rural, observa-se que os indígenas apresentam a pirâmide com base mais alargada em relação aos não-indígenas, em especial na faixa etária mais jovem (0 a 14 anos de idade). As populações rurais são mais jovens que as urbanas. Na situação rural indígena, as faixas mais jovens, em especial de 0 a 4 anos, são mais presentes na população que na situação urbana.

Os perfis das pirâmides tanto para homens quanto mulheres na situação rural, quando comparamos indígenas e não-indígenas a partir dos 14 anos de idade são bastante semelhantes. Na situação urbana, os não-indígenas apresentam maior alargamento nas faixas etárias entre 10 e 29 anos. Na mesma situação, os indígenas atingem o maior percentual da população na faixa dos 0 a 4 anos. 
Tabela 4: População urbana alfabetizada (\% Alfab.) conforme categorias de idade e de cor/raça nas microrregiões analisadas segundo o Censo Demográfico 2010. Amazonas.

\begin{tabular}{|c|c|c|c|c|c|c|c|c|c|}
\hline \multirow{2}{*}{\multicolumn{2}{|c|}{ Microrregião }} & \multicolumn{2}{|c|}{ BRANCA } & \multicolumn{2}{|c|}{ PRETA } & \multicolumn{2}{|c|}{ PARDA } & \multicolumn{2}{|c|}{ INDÍGENA } \\
\hline & & $\%$ Alfab. & Total & $\%$ Alfab. & Total & $\%$ Alfab. & Total & $\%$ Alfab. & Total \\
\hline \multirow{8}{*}{ 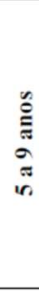 } & Alto Solimões & 59,1 & 2184 & 52,2 & 345 & 53,8 & 12903 & 51,5 & 1001 \\
\hline & Boca do Acre & 55,0 & 971 & 42,9 & 154 & 51,1 & 2265 & 29,9 & 67 \\
\hline & Madeira & 66,1 & 2529 & 55,8 & 369 & 61,6 & 7354 & 50,0 & 128 \\
\hline & Manaus & 68,5 & 46691 & 60,7 & 5508 & 64,4 & 124623 & 46,9 & 789 \\
\hline & Parintins & 65,8 & 2679 & 66,5 & 281 & 64,8 & 13724 & 60,9 & 115 \\
\hline & Purus & 57,1 & 1300 & 49,4 & 154 & 54,7 & 3401 & 37,7 & 204 \\
\hline & Rio Negro & 75,6 & 639 & 77,3 & 194 & 75,0 & 2806 & 83,7 & 1704 \\
\hline & SUBTOTAL* & 67,5 & 56993 & 60,1 & 7005 & 63,3 & 167076 & 63,4 & 4008 \\
\hline \multirow{8}{*}{ 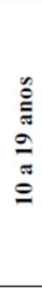 } & Alto Solimões & 95,9 & 3952 & 92,9 & 776 & 94,9 & 24747 & 92,8 & 1877 \\
\hline & Boca do Acre & 95,0 & 1812 & 89,9 & 326 & 93,0 & 4468 & 78,6 & 112 \\
\hline & Madeira & 97,4 & 5025 & 94,9 & 918 & 96,7 & 15933 & 95,3 & 149 \\
\hline & Manaus & 97,8 & 93186 & 96,3 & 14363 & 97,3 & 269647 & 92,4 & 1401 \\
\hline & Parintins & 97,6 & 5351 & 95,2 & 784 & 97,7 & 28080 & 96,6 & 319 \\
\hline & Purus & 94,9 & 2453 & 92,8 & 377 & 94,4 & 7118 & 85,7 & 315 \\
\hline & Rio Negro & 98,4 & 1289 & 97,3 & 407 & 97,9 & 5756 & 97,7 & 3419 \\
\hline & SUBTOTAL* & 97,6 & 113068 & 95,8 & 17951 & 97,0 & 355749 & 94,7 & 7592 \\
\hline \multirow{8}{*}{ 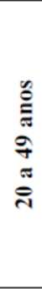 } & Alto Solimões & 92,3 & 6873 & 85,7 & 1709 & 90,6 & 39910 & 83,0 & 2640 \\
\hline & Boca do Acre & 86,4 & 3175 & 75,4 & 723 & 80,8 & 7294 & 70,6 & 194 \\
\hline & Madeira & 94,9 & 8901 & 87,8 & 2014 & 91,6 & 25181 & 79,6 & 240 \\
\hline & Manaus & 98,1 & 237792 & 95,8 & 43501 & 97,4 & 629790 & 92,2 & 2951 \\
\hline & Parintins & 96,7 & 7832 & 94,7 & 1485 & 97,1 & 43408 & 94,1 & 376 \\
\hline & Purus & 84,6 & 3748 & 73,8 & 869 & 81,4 & 11433 & 67,1 & 462 \\
\hline & Rio Negro & 97,1 & 2628 & 94,8 & 944 & 95,2 & 9522 & 94,5 & 5824 \\
\hline & SUBTOTAL* & 97,5 & 270949 & 94,5 & 51245 & 96,4 & 766538 & 89,9 & 12687 \\
\hline \multirow{8}{*}{ 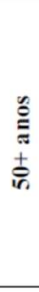 } & Alto Solimões & 66,9 & 1877 & 55,0 & 573 & 59,2 & 10317 & 42,0 & 789 \\
\hline & Boca do Acre & 59,3 & 1009 & 35,3 & 286 & 47,8 & 2226 & 32,8 & 67 \\
\hline & Madeira & 76,8 & 2848 & 53,9 & 749 & 63,9 & 7844 & 39,2 & 79 \\
\hline & Manaus & 91,4 & 69814 & 80,9 & 13052 & 86,3 & 163758 & 67,9 & 1124 \\
\hline & Parintins & 84,0 & 3119 & 74,5 & 664 & 81,7 & 14656 & 69,3 & 101 \\
\hline & Purus & 47,7 & 1149 & 35,8 & 344 & 39,8 & 3227 & 24,5 & 188 \\
\hline & Rio Negro & 81,7 & 759 & 67,8 & 320 & 73,6 & 2544 & 67,6 & 2051 \\
\hline & SUBTOTAL* & 88,9 & 80575 & 76,4 & 15988 & 82,4 & 204572 & 60,2 & 4399 \\
\hline & TOTAL ** & 92,9 & 521585 & 89,0 & 92189 & 90,9 & 1493935 & 82,9 & 28686 \\
\hline
\end{tabular}

Fonte: SIDRA/IBGE. Tabela 1379. Censo Demográfico 2010. Resultados do Universo.

* SUBTOTAL: Valor para cada faixa etária considerando o agregado das microrregiões analisadas.

** TOTAL: Valor considerando o agregado das categorias de idade e das microrregiões analisadas: Alto Solimões, Boca do Acre, Madeira, Manaus, Parintins, Purus, Rio Negro.

Considerando o agregado das microrregiões analisadas e todas as categorias de idade, os indígenas possuem o menor percentual de população alfabetizada $(82,9 \%)$, atrás dos pretos $(89,0 \%)$, pardos $(90,9 \%)$ e brancos $(92,9)$. Nota-se uma exceção na microrregião do Rio Negro na faixa etária dos 5 a 9 anos de idade, em que o percentual de população indígena alfabetizada é o maior $(83,7 \%)$ dentre as categorias de cor/raça analisadas.

Outra microrregião, além do caso citado para o Rio Negro, onde os brancos não possuem o maior percentual de alfabetização é Parintins nas 3 categorias iniciais (que vai de 5 até 49 anos de idade), em que os pretos e os pardos possuem maior percentual de alfabetização.

Os menores percentuais de alfabetização em todas as categorias de cor/raça são observados na faixa etária dos 5 a 9 anos. Porém, para os indígenas o menor percentual de alfabetizados é observado na faixa dos 50 ou mais anos. Na transição dos 10 a 19 para 20 a 49 anos os indígenas têm maior redução (5\% aproximadamente) no percentual de alfabetizados 
Espaço Ameríndio

(pouco mais de $1 \%$ para as demais categorias de cor/raça), ocorrendo o mesmo na transição para a faixa dos 50 ou mais anos de idade, observando-se para os indígenas uma redução na alfabetização de quase $30 \%$, enquanto que para as demais a redução não supera pouco mais de $18 \%$.

Comparando-se as três microrregiões com maior população urbana indígena, Alto Solimões, Manaus e Rio Negro, observa-se que a última possui os maiores percentuais de alfabetização para as 3 primeiras faixas etárias (dos 5 até os 49 anos), sendo que na faixa dos 50 ou mais anos de idade, o percentual de alfabetizados é ligeiramente menor $(0,3 \%)$ quando comparado com Manaus. Esta última microrregião tem os menores percentuais de alfabetização considerando as duas primeiras faixas etárias, que vão dos 5 aos 19 anos.

Tabela 5: População urbana indígena e não indígena*** alfabetizada conforme categorias de idade e sexo nas microrregiões analisadas segundo o Censo Demográfico 2010. Amazonas.

\begin{tabular}{|c|c|c|c|c|c|c|c|c|c|}
\hline & \multirow{3}{*}{ Microrregião } & \multicolumn{4}{|c|}{ MASCULINO } & \multicolumn{4}{|c|}{ FEMININO } \\
\hline & & \multicolumn{2}{|c|}{ Não-indígena } & \multicolumn{2}{|c|}{ Indígena } & \multicolumn{2}{|c|}{ Não-indígena } & \multicolumn{2}{|c|}{ Indígena } \\
\hline & & $\%$ Alfab. & Total & $\%$ Alfab. & Total & $\%$ Alfab. & Total & $\%$ Alfab. & Total \\
\hline \multirow{8}{*}{ 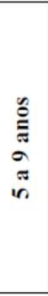 } & Alto Solimões & 45,9 & 10611 & 39,8 & 4691 & 49,2 & 10413 & 38,2 & 4463 \\
\hline & Boca do Acre & 44,1 & 3006 & 15,0 & 220 & 46,2 & 2815 & 26,3 & 213 \\
\hline & Madeira & 51,6 & 9538 & 37,8 & 825 & 55,3 & 9069 & 39,8 & 809 \\
\hline & Manaus & 62,5 & 97767 & 36,6 & 894 & 65,7 & 94038 & 36,4 & 888 \\
\hline & Parintins & 56,1 & 15665 & 57,4 & 977 & 59,2 & 14923 & 58,8 & 960 \\
\hline & Purus & 41,7 & 4143 & 21,8 & 444 & 46,1 & 3961 & 23,6 & 407 \\
\hline & Rio Negro & 67,8 & 2621 & 56,3 & 3297 & 71,2 & 2690 & 57,1 & 3228 \\
\hline & SUBTOTAL * & 59,0 & 143351 & 44,5 & 11348 & 62,2 & 137909 & 44,8 & 10968 \\
\hline \multirow{8}{*}{ 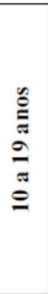 } & Alto Solimões & 89,4 & 19952 & 78,0 & 7733 & 92,0 & 19307 & 77,1 & 7413 \\
\hline & Boca do Acre & 86,2 & 5760 & 59,7 & 335 & 90,1 & 5230 & 62,5 & 339 \\
\hline & Madeira & 92,3 & 19643 & 70,6 & 1292 & 94,7 & 18158 & 71,7 & 1200 \\
\hline & Manaus & 96,3 & 201586 & 86,0 & 1512 & 97,8 & 203533 & 90,2 & 1393 \\
\hline & Parintins & 95,1 & 29459 & 92,2 & 1498 & 96,9 & 27557 & 90,6 & 1524 \\
\hline & Purus & 86,2 & 7919 & 60,3 & 638 & 90,6 & 7457 & 64,3 & 613 \\
\hline & Rio Negro & 93,9 & 5605 & 71,0 & 5827 & 94,9 & 5515 & 71,4 & 5702 \\
\hline & SUBTOTAL * & 94,9 & 289924 & 76,2 & 18835 & 96,8 & 286757 & 76,4 & 18184 \\
\hline \multirow{8}{*}{ 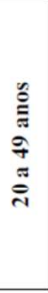 } & Alto Solimões & 86,5 & 32365 & 74,8 & 11594 & 86,0 & 30205 & 62,6 & 10252 \\
\hline & Boca do Acre & 76,1 & 9446 & 63,6 & 533 & 78,0 & 8461 & 49,6 & 468 \\
\hline & Madeira & 88,3 & 32801 & 68,7 & 1932 & 89,3 & 29235 & 69,3 & 1641 \\
\hline & Manaus & 96,5 & 468722 & 86,8 & 2598 & 97,5 & 488182 & 88,4 & 2473 \\
\hline & Parintins & 95,0 & 44464 & 91,9 & 2075 & 96,5 & 40403 & 82,0 & 1810 \\
\hline & Purus & 74,4 & 13763 & 60,0 & 899 & 76,8 & 11957 & 46,6 & 770 \\
\hline & Rio Negro & 89,1 & 10799 & 70,2 & 9320 & 91,2 & 8829 & 67,5 & 8377 \\
\hline & SUBTOTAL * & 94,5 & 612360 & 74,5 & 28951 & 95,7 & 617272 & 67,8 & 25791 \\
\hline \multirow{8}{*}{ 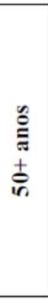 } & Alto Solimões & 60,2 & 9942 & 34,5 & 3281 & 48,4 & 8728 & 19,0 & 2901 \\
\hline & Boca do Acre & 46,6 & 3265 & 25,1 & 195 & 42,8 & 2877 & 9,9 & 162 \\
\hline & Madeira & 63,9 & 11907 & 42,4 & 689 & 55,6 & 9525 & 40,1 & 466 \\
\hline & Manaus & 86,0 & 136745 & 65,9 & 948 & 84,8 & 156022 & 55,1 & 1101 \\
\hline & Parintins & 79,7 & 17687 & 63,3 & 547 & 75,0 & 15526 & 36,7 & 622 \\
\hline & Purus & 42,0 & 4603 & 20,7 & 406 & 37,0 & 3823 & 14,3 & 315 \\
\hline & Rio Negro & 70,5 & 3391 & 53,5 & 3614 & 64,3 & 2631 & 42,6 & 3513 \\
\hline & SUBTOTAL * & 80,6 & 187540 & 46,1 & 9680 & 79,2 & 199132 & 34,5 & 9080 \\
\hline & TOTAL $* *$ & 88,4 & 1233175 & 66,0 & 68814 & 89,6 & 1241070 & 61,5 & 64023 \\
\hline
\end{tabular}

Fonte: SIDRA/IBGE. Tabela 3176. Censo Demográfico 2010. Resultados do Universo.

* SUBTOTAL: Valor para cada faixa etária considerando o agregado das microrregiões analisadas.

** TOTAL: Valor considerando o agregado das categorias de idade e das microrregiões analisadas: Alto Solimões, Boca do Acre, Madeira, Manaus, Parintins, Purus, Rio Negro.

*** Não-indígena inclui as categorias branca, preta, amarela e parda. 
Considerando o agregado de idades e microrregiões, os indígenas possuem percentuais de alfabetização menores (66\% e $61,5 \%$ para homens e mulheres, respectivamente) que os não-indígenas $(88,4 \%$ e $89,6 \%$ para homens e mulheres, respectivamente). Os homens indígenas possuem percentual mais elevado (66\%) que as mulheres indígenas $(61,5 \%)$.

Quando se considera o conjunto das microrregiões por faixa etária, comparando-se homens e mulheres indígenas, as mulheres possuem percentual ligeiramente maior que os homens até a faixa etária dos 10 a 19 anos. Na faixa dos 20 a 49 anos estas apresentam percentuais aproximadamente $7 \%$ menores que os homens. Na faixa dos 50 anos ou mais esta diferença se aproxima de $12 \%$, com vantagem aos últimos. Nesta última faixa etária, existem microrregiões que, embora tenham população indígena reduzida, apresentam percentuais reduzidos de alfabetização, tais como Boca do Acre e Purus, novamente estando as mulheres com os menores percentuais $(9,9 \%$ e $14,3 \%$, respectivamente) em relação aos homens $(25,1 \%$ e $20,7 \%$, respectivamente) nestas microrregiões.

Comparando-se as três microrregiões com maior população urbana indígena, Alto Solimões, Manaus e Rio Negro, observamos que esta última possui os maiores percentuais de alfabetização na faixa etária dos 5 a 9 anos para homens e mulheres, apresentando percentuais maiores inclusive que os não-indígenas. Manaus, entretanto, possui os maiores percentuais nas demais faixas etárias (10 anos em diante) quando comparada com as demais microrregiões tanto para homens quanto mulheres indígenas e não-indígenas. Comparando-se a disparidade entre percentuais de alfabetização nas faixas etárias de indígenas e não indígenas nas microrregiões (sempre com desvantagem para os primeiros), observamos que na faixa dos 5 a 9 anos de idade, Manaus possui a maior disparidade, com quase $30 \%$ a mais para os não-indígenas. Nas duas faixas etárias seguintes (que vão de 10 a 49 anos), Manaus possui a menor disparidade entre indígenas e não-indígenas (não maior que 10\%); na faixa dos 50 ou mais anos de idade, Rio Negro possui as menores disparidades entre indígenas e não indígenas tanto para homens (17\% aprox.) quanto para mulheres (22\% aprox.).

Comparando-se as diferenças entre os percentuais de alfabetização entre indígenas e não indígenas nas 3 microrregiões (Alto Solimões, Manaus e Rio Negro) entre os sexos, observamos que a maior disparidade se encontra nas mulheres, considerando todas as idades e microrregiões, com exceção de Manaus nas faixas de 10 a 19 anos (8\% aprox. de diferença entre as mulheres não indígenas para as indígenas, enquanto que a dos homens está em $10 \%$ aprox..) e 20 a 49 anos (9\% aprox. de diferença entre as mulheres não indígenas para as indígenas, e a dos homens em 10\% aprox.). Excetuando-se estes casos, observa-se menor disparidade de alfabetização entre homens não-indígenas e indígenas, quando comparados às mulheres, indicando uma situação duplamente desfavorável para a mulher indígena em relação ao homem não indígena. 
Espaço Ameríndio

Tabela 6: Classe de rendimento nominal da população indígena com 10 ou mais anos de idade nas microrregiões conforme categoria de cor/raça e faixa etária segundo o

Censo Demográfico 2010. Amazonas

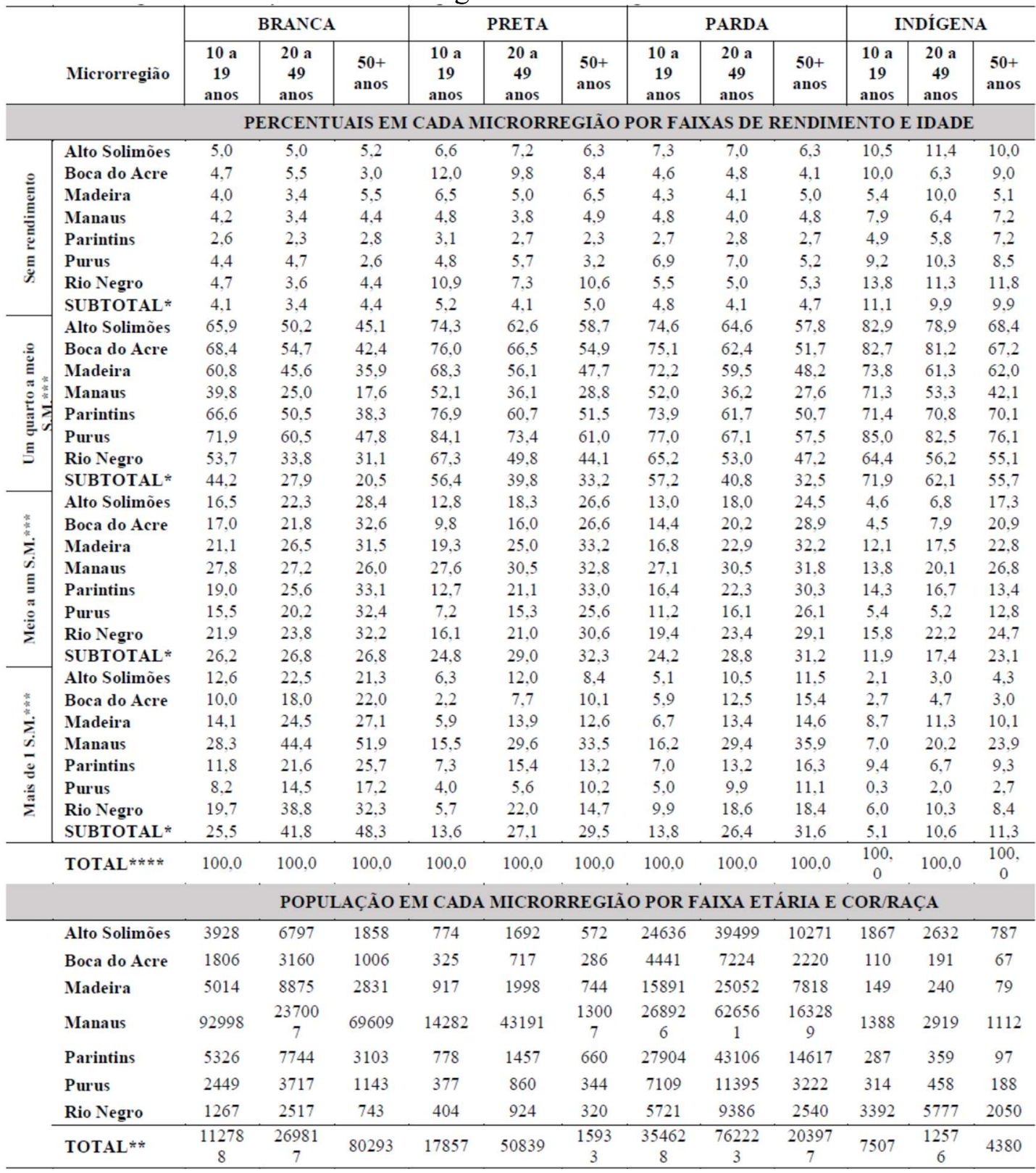

Fonte: SIDRA/IBGE. Tabela 3278. Censo Demográfico 2010. Resultados do Universo.

* SUBTOTAL: Valor para cada faixa de rendimento e idade considerando o agregado das microrregiões analisadas.

** TOTAL: Valor considerando o agregado das microrregiões analisadas para cada faixa etária: Alto Solimões, Boca do Acre, Madeira, Manaus, Parintins, Purus, Rio Negro.

*** S.M.: Salário mínimo utilizado de R \$ 510,00 (quintentos e dez reais).

**** Somatório dos valores subtotais percentuais de cada faixa etária e cor/raça, considerando a população do agregado nas microrregiões analisadas.

Os indígenas estão mais concentrados na faixa salarial entre um quarto a meio salário mínimo, apresentando os maiores percentuais nesta faixa salarial em todas idades quando comparados às demais categorias de cor/raça. A segunda maior concentração dos indígenas está na faixa de meio a um salário mínimo, porém nesta apresentam os menores percentuais quando comparados às demais categorias de cor/raça. A 
terceira categoria que concentra os indígenas é a "sem rendimento", possuindo os maiores percentuais por faixa etária que as demais categorias de cor/raça. A faixa de rendimento onde os indígenas estão menos presentes é a de mais de um salário mínimo, em todas as categorias de idade, com os menores percentuais observados. Os brancos são os mais presentes nesta última faixa de rendimento.

Observa-se, para todas as categorias de cor/raça, que a partir da faixa de renda de meio a um salário mínimo em diante, a faixa etária dos 50 ou mais anos de idade se destaca com os maiores percentuais. Para a faixa de renda de um quarto a meio salário mínimo, os mais frequentes são os mais jovens, de 10 a 19 anos, enquanto que os acima dos 50 anos são os menos frequentes. A categoria "sem renda" concentra as faixas etárias extremas, tanto a dos mais jovens (10 a 19 anos) quanto a dos mais velhos (50 ou mais anos de idade), não sendo tão evidente esta tendência para os indígenas. Com relação às microrregiões, observa-se que Rio Negro, seguido por Alto Solimões e Purus, têm as maiores frequências de indígenas "sem rendimento".

Comparando-se as três microrregiões com maior população indígena urbana (Alto Solimões, Manaus e Rio Negro), observamos que Manaus é a microrregião com maiores percentuais na faixa salarial "mais de um S.M.", seguida pelo Rio Negro. Esta última microrregião tem os maiores percentuais nas faixas etárias na categoria de "meio a um S.M." (com exceção somente da faixa dos 50 ou mais anos de idade), seguida por Manaus. Alto Solimões apresenta os maiores percentuais em todas faixas etárias na categoria de "um quarto a meio S.M.". Na categoria "sem rendimento", Rio Negro e Alto Solimões apresentam percentuais mais elevados semelhantes entre si, entretanto, maiores que os observados para todas as faixas etárias em Manaus.

Os indígenas possuem os percentuais mais prejudicados em três dos itens analisados: "existência de bueiros/boca de lobo" e de "calçadas", além de "existência de esgoto a céu aberto". Apresentam diferenças percentuais de aproximadamente $20 \%$ nos três itens quando comparados a pretos ou pardos nas três categorias mencionadas. Os brancos apresentam os melhores percentuais nestes itens. Somente no item "ausência de acúmulo de lixo nos logradouros" os indígenas apresentam percentuais melhores $(6,5 \%)$ que pretos $(6,9 \%)$ e pardos $(6,7 \%)$, ficando atrás somente dos brancos (5,5\%).

Considerando o agregado das microrregiões, o item com maior disparidade dos indígenas para os brancos é a "existência de calçadas", havendo uma diferença $36 \%$ maior para os últimos. No item "existência de bueiro/boca de lobo" existe também uma grande diferença, de mais de $25 \%$ entre brancos e indígenas. No item "existência de esgoto a céu aberto" os indígenas apresentam um percentual quase $20 \%$ maior que o apresentado pela cor/raça branca.

Considerando as microrregiões, observam-se em Manaus maiores frequências de existência nos itens "existência de calçadas" e de "bocas de lobo/bueiro" para todas as categorias de cor/raça, e menores para "existência de esgoto a céu aberto". Porém, neste terceiro item, a diferença dos percentuais entre Manaus e as demais microrregiões é 
menor. Para o item "existência de lixo nos logradouros" não é possível visualizar a mesma tendência favorável à Manaus. Ressalta-se também que o observado nos três primeiros itens, com vantagem para Manaus em relação às demais microrregiões, é atenuado quando consideramos a categoria dos indígenas.

Tabela 7: Características do entorno do domicílio para as categorias nas microrregiões analisadas segundo o Censo Demográfico 2010. Amazonas.

\begin{tabular}{|c|c|c|c|c|c|c|c|c|c|}
\hline \multirow{2}{*}{ Item } & \multirow[b]{2}{*}{ Microrregião } & \multicolumn{2}{|c|}{ BRANCA } & \multicolumn{2}{|c|}{ PRETA } & \multicolumn{2}{|c|}{ PARDA } & \multicolumn{2}{|c|}{ INDÍGENA } \\
\hline & & $\%$ casos & Total & $\begin{array}{c}\% \\
\text { casos }\end{array}$ & Total & $\%$ casos & Total & $\%$ casos & Total \\
\hline \multirow{8}{*}{ 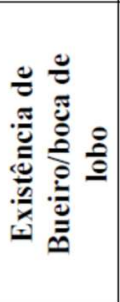 } & Alto Solimões & 28,9 & 16792 & 25,1 & 3409 & 23,7 & 97238 & 10,2 & 6552 \\
\hline & Boca do Acre & 14,1 & 8071 & 11,0 & 1587 & 12,8 & 17950 & 8,8 & 509 \\
\hline & Madeira & 29,4 & 21720 & 30,2 & 4250 & 23,0 & 62129 & 27,8 & 681 \\
\hline & Manaus & 45,7 & 495191 & 41,3 & 79169 & 40,7 & 1277444 & 22,4 & 6877 \\
\hline & Parintins & 17,1 & 20248 & 16,1 & 2973 & 15,0 & 101681 & 7,5 & 855 \\
\hline & Purus & 27,2 & 9797 & 24,7 & 1770 & 25,0 & 27561 & 17,9 & 1346 \\
\hline & Rio Negro & 26,0 & 5872 & 26,1 & 1973 & 21,7 & 23166 & 14,5 & 14661 \\
\hline & SUBTOTAL * & 42,6 & 577691 & 38,3 & 95131 & 36,5 & 1607169 & 15,5 & 31481 \\
\hline \multirow{8}{*}{ 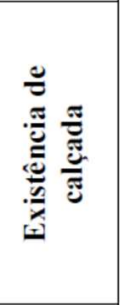 } & Alto Solimões & 16,8 & 16792 & 12,6 & 3409 & 12,3 & 97238 & 7,5 & 6552 \\
\hline & Boca do Acre & 9,8 & 8071 & 6,5 & 1587 & 8,0 & 17950 & 3,1 & 509 \\
\hline & Madeira & 11,3 & 21720 & 8,4 & 4250 & 11,1 & 62129 & 3,7 & 681 \\
\hline & Manaus & 54,9 & 495191 & 43,1 & 79169 & 44,6 & 1277444 & 25,6 & 6877 \\
\hline & Parintins & 38,8 & 20248 & 34,3 & 2973 & 35,2 & 101681 & 36,0 & 855 \\
\hline & Purus & 20,9 & 9797 & 15,5 & 1770 & 17,3 & 27561 & 9,1 & 1346 \\
\hline & Rio Negro & 24,7 & 5872 & 16,8 & 1973 & 20,6 & 23166 & 11,5 & 14661 \\
\hline & SUBTOTAL * & 50,0 & 577691 & 38,5 & 95131 & 39,5 & 1607169 & 14,0 & 31481 \\
\hline \multirow{8}{*}{ 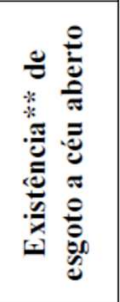 } & Alto Solimões & 64,4 & 16792 & 63,1 & 3409 & 62,6 & 97238 & 38,8 & 6552 \\
\hline & Boca do Acre & 41,3 & 8071 & 34,6 & 1587 & 41,2 & 17950 & 37,5 & 509 \\
\hline & Madeira & 32,2 & 21720 & 41,1 & 4250 & 38,7 & 62129 & 37,9 & 681 \\
\hline & Manaus & 19,6 & 495191 & 20,8 & 79169 & 21,3 & 1277444 & 29,6 & 6877 \\
\hline & Parintins & 33,9 & 20248 & 34,2 & 2973 & 32,0 & 101681 & 31,3 & 855 \\
\hline & Purus & 50,0 & 9797 & 50,0 & 1770 & 48,6 & 27561 & 39,2 & 1346 \\
\hline & Rio Negro & 43,7 & 5872 & 47,2 & 1973 & 47,8 & 23166 & 53,0 & 14661 \\
\hline & SUBTOTAL * & 23,0 & 577691 & 24,9 & 95131 & 26,3 & 1607169 & 43,2 & 31481 \\
\hline \multirow{8}{*}{ 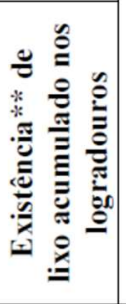 } & Alto Solimões & 12,1 & 16792 & 15,3 & 3409 & 12,1 & 97238 & 10,8 & 6552 \\
\hline & Boca do Acre & 7,6 & 8071 & 7,2 & 1587 & 7,5 & 17950 & 14,3 & 509 \\
\hline & Madeira & 5,4 & 21720 & 8,0 & 4250 & 10,7 & 62129 & 6,0 & 681 \\
\hline & Manaus & 5,1 & 495191 & 6,0 & 79169 & 6,5 & 1277444 & 7,3 & 6877 \\
\hline & Parintins & 3,8 & 20248 & 2,9 & 2973 & 3,5 & 101681 & 2,3 & 855 \\
\hline & Purus & 19,6 & 9797 & 25,6 & 1770 & 19,3 & 27561 & 19,2 & 1346 \\
\hline & Rio Negro & 2,9 & 5872 & 3,3 & 1973 & 2,2 & 23166 & 3,0 & 14661 \\
\hline & SUBTOTAL* & 5,5 & 577691 & 6,7 & 95131 & 6,9 & 1607169 & 6,5 & 31481 \\
\hline
\end{tabular}

Fonte: SIDRA/IBGE. Tabela 3358. Censo Demográfico 2010. Resultados do Universo.

* SUBTOTAL: Valor total para cada cor/raça considerando o agregado das microrregiões analisadas em um dos itens do entorno do domicílio analisados.

** Trata-se de itens onde o desejado seria uma menor frequência, tendo em vista serem características do entorno do domicílio indesejadas.

Quando consideramos as três microrregiões com as maiores populações indígenas urbana (Alto Solimões, Manaus e Rio Negro), a disparidade nas frequências apresentadas por brancos e indígenas nos itens existência de "calçadas", "bueiros/bocas de lobo" é maior em Manaus, aproximadamente $23 \%$ e $27 \%$, nos itens mencionados, respectivamente. Para os itens existência de "esgoto a céu aberto" e de "lixo nos logradouros", Alto Solimões apresenta melhores indicadores para os indígenas em relação aos brancos, diferenciando do padrão observado nos itens anteriores e nas demais microrregiões. Cabe 
ressaltar que para o item "existência de esgoto a céu aberto", os indígenas têm percentuais quase $26 \%$ menores que os brancos no Alto Solimões. No item "existência de lixo acumulado nos logradouros", para o Rio Negro, o percentual dos indígenas é semelhante ao dos brancos $(0,1 \%$ de diferença), enquanto que em Manaus a vantagem dos brancos é de pouco mais de $2 \%$.

\section{Discussão}

Observa-se, para os indígenas urbanos no estado do Amazonas, a concentração em três grandes microrregiões: Alto Solimões, Manaus e Rio Negro, contabilizando $85,1 \%$ desta população (34.302 indivíduos). $\mathrm{Na}$ situação urbana, a maior parte da população indígena possui até 19 anos de idade, enquanto que os não indígenas possuem maiores percentuais de população acima dos 19 anos de idade. As mulheres estão ligeiramente mais presentes em situação urbana $(50,2 \%)$ que os homens indígenas $(49,8 \%)$. Os indígenas possuem o menor percentual de alfabetização comparados com as demais categorias de cor/raça, com situação mais desfavorável na faixa etária dos 50 ou mais anos de idade. Existe maior disparidade entre percentuais de alfabetização de mulheres e homens indígenas, com prejuízo para as primeiras. Os indígenas se concentram na faixa de um quarto a meio salário mínimo e constituem a categoria de cor/raça mais frequente na categoria "sem rendimento", sendo os menos frequentes na categoria "mais de um salário mínimo". Relativo às características do entorno do domicílio, são a categoria de cor/raça que apresenta os indicadores mais desfavoráveis em três dos quesitos analisados, com exceção de "existência de lixo acumulado nos logradouros". Observam-se, no geral, variações importantes no comportamento das frequências das categorias de cor/raça conforme a microrregião e os itens analisados.

Sete das 13 microrregiões em situação urbana apresentam população indígena superior a 500 indivíduos. A microrregião de Manaus é a única onde o número absoluto de indígenas nesta situação supera os em situação rural. Coimbra Jr. e Santos (2000) citam, como fatores ligados à migração de indígenas para as cidades, a possibilidade de absorção nos mercados regionais e a busca por melhor infraestrutura no oferecimento de serviços básicos. Tal observação é confirmada por Teixeira et al. (2009) no contexto do estado do Amazonas, em que identificou fluxos migratórios significativos de indígenas para a cidade de Manaus, coincidindo com o período de implantação da Zona Franca em meados da década de 1960 para 1970.

As mulheres indígenas são mais presentes na situação urbana, tendência já observada em Censos anteriores (IBGE, 2005) e confirmado mais recentemente (IBGE, 2012). Quando comparadas as pirâmides etária dos indígenas e não-indígenas, observa-se que, em ambas situações de domicílio, os primeiros apresentam base da pirâmide mais alargada, indicando crescimento demográfico acentuado, fato já observado em resultados de Censos anteriores (IBGE, 2005). 
Comparando-se os indígenas em ambas situações de domicílio, a pirâmide para a área rural tem base mais alargada indicando na área rural a ocorrência de maiores índices de fecundidade em comparação com a área urbana. Análises provenientes do Censo de 2010 (IBGE, 2011) reforçam esta tendência na população brasileira, apresentando uma pirâmide etária com base mais larga na situação rural comparada com a urbana.

Os indígenas constituem a categoria de cor/raça com os menores indicadores socioeconômicos considerados (faixa de rendimento e percentual de alfabetização). A desvantagem socioeconômica dos indígenas frente às demais categorias da população nacional é observada em diversos países (GRACEY \& KING, 2009; AGOSTINI et al., 2010), mesmo nos desenvolvidos tais como Canadá, Austrália e Nova Zelândia (MITROU et al., 2014), sendo realidade também no Brasil (COIMBRA \& SANTOS, 2000; IBGE, 2005; SANTOS \& PEREIRA, 2005; IBGE, 2012).

Destaca-se que em algumas microrregiões e para algumas das variáveis analisadas, tais como percentual de alfabetização no Rio Negro e no item do entorno do domicílio "existência de lixo acumulado no logradouro" no Alto Solimões, observaram-se padrões diferenciados, com pretos, pardos ou mesmo brancos apresentando percentuais menos adequados que os indígenas. O fato das microrregiões serem áreas territoriais extensas e com grande diversidade socioeconômica, geográfica e cultural deve ser considerado, influenciando nos resultados encontrados. Consistente com esta observação, de que nem sempre os indígenas apresentam os piores indicadores, Mainbourg et al. (2006), comparando as condições peri-domiciliares de indígenas e não-indígenas em Manaus, encontrou condições melhores em alguns itens pesquisados em uma etnia indígena em especial, mesmo quando comparados com os vizinhos não-indígenas, explicando tal fato, dentre outros motivos, pelo maior tempo de migração e estabelecimento de conexões com o território desta etnia em especial (MAINBOURG et al., 2006).

Considerando somente os indígenas, nota-se diferenciação entre os percentuais de alfabetização masculino e feminino, com maiores percentuais para o primeiro grupo, em especial nas faixas etárias a partir dos 20 anos de idade. Tal observação coincide com a análise dos Censos de 1990 e 2000, com a diferença de que tal fenômeno ocorria em idade mais jovem - a partir dos 15 anos de idade o analfabetismo era maior nas mulheres indígenas (IBGE, 2005). A expansão da oferta de vagas no sistema educacional, com a incorporação dos indígenas em escolas, em especial na situação urbana, pode estar relacionada aos maiores percentuais de alfabetização das mulheres indígenas até os 19 anos de idade em relação aos homens. Porém, a partir da faixa dos 20 anos de idade, as mulheres indígenas apresentam percentuais de alfabetização quase $10 \%$ menores que os homens, podendo tal fato estar representando a parcela da população que por algum motivo (trabalho, constituição de família, etc.) não está inclusa nas políticas de expansão das vagas no sistema educacional.

Os indígenas concentram-se nas faixas de rendimento mais baixas, sendo maioria na faixa entre um quarto a meio salário mínimo, em todas 
as idades consideradas. Os indígenas são também a categoria de cor/raça com os maiores percentuais na faixa "sem rendimento", para todas as idades. Esta tendência foi observada em Censos anteriores (IBGE, 2005) realizados no Brasil. Os maiores percentuais nas faixas de rendimento superior ( 1 ou mais salários mínimos) em todas as categorias de cor/raça foram observados nas faixas etárias superiores, em especial na dos 50 ou mais anos de idade, não sendo tão aparente esta observação para os indígenas.

Quanto à situação de entorno do domicílio, os indígenas apresentam os menores percentuais de melhorias de infraestrutura (existência de calçada, de bueiro/boca de lobo, ausência de esgoto a céu aberto e de lixo acumulado nos logradouros), embora no quesito "ausência lixo acumulado nos logradouros" apresentem percentuais maiores que pretos e pardos. Estudo de Mainbourg et al. (2006), comparando condições peridomiciliares de indígenas de diversas etnias e não-indígenas na cidade de Manaus, indicou variações nos resultados entre as etnias consideradas, com vantagem para aquelas etnias com estabelecimento mais antigo na cidade (Sateré-Mawé e Tikuna). Estas etnias estabelecidas há mais tempo na cidade apresentaram melhores indicadores, inclusive, que os nãoindígenas. Estudo de Botelho e Weigel (2011), entretanto, analisando uma comunidade Sateré-Mawé na cidade de Manaus, relata condições peridomiciliares precárias.

Deve ser considerado, na discussão sobre entorno do domicílio, o próprio conceito de setor urbano compreendido pelo IBGE, que abrange tanto "áreas urbanizadas" quanto "áreas não urbanizadas"4 (IBGE, 2013). Embora $79,1 \%$ da população total do Amazonas esteja classificada como urbana (IBGE, 2011), não há como diferenciar a parcela desta população que estaria domiciliada em setores urbanos de áreas não-urbanizadas, tampouco a parcela desta população que deixou de ser considerada nas captações de dados sobre características de entorno do domicílio por não residir em áreas com ordenamento urbano regular (IBGE, 2010a), critério utilizado pelo IBGE na captação destes dados.

\section{Conclusão}

Os resultados encontrados confirmam nas microrregiões do estado do Amazonas, a situação de desvantagem socioeconômica dos indígenas em situação urbana quando comparados com as demais categorias de cor/raça, em especial aos brancos. Os homens indígenas em área urbana possuem percentuais de alfabetização maiores que as mulheres a partir da faixa etária dos 19 anos. Os indígenas urbanos concentram-se nas faixas de rendimento mais baixas, acompanhando com menor intensidade a tendência mostrada por outras categorias de cor/raça, de aumento no rendimento em faixas etárias mais avançadas. As condições

\footnotetext{
${ }^{4}$ Setor urbano de área urbanizada prevê 250 a 400 domicílios no setor censitário, a serem pesquisados em até 30 dias. Setor urbano de área não-urbanizada prevê 100 a 250 domicílios ou de 100 a 200 estabelecimentos agropecuários com um tempo cobertura do setor censitário maior no segundo caso, de 45 dias (IBGE, 2013, p. 378).
} 
de entorno do domicílio, embora devam ser consideradas com algumas ressalvas quanto à metodologia de coleta dos dados, para os indígenas urbanos (com especial foco nos itens relacionados à infraestrutura urbana e ao saneamento básico) apresentam percentuais que demonstram desvantagem em relação às demais categorias de cor/raça. Existem, entretanto, variações importantes conforme a microrregião analisada.

O estudo proporcionou visibilidade para indicadores socioeconômicos e demográficos dos indígenas em situação urbana no estado do Amazonas, a partir da análise de suas microrregiões. Proporcionou também um aprofundamento nas análises de caráter mais regionalizado, considerando o estado brasileiro com maior população indígena em termos quantitativos. Complementou os dados nacionais divulgados pelo IBGE referentes à situação socioeconômica e demográfica dos indígenas no Censo Demográfico de 2010. Entre os achados do estudo, ressaltamos o reforço da situação de desvantagem socioeconômica desta população frente à população não-indígena no Brasil.

Destaca-se, entretanto, que a opção de análise por microrregiões agrega ainda uma grande diversidade étnico-cultural, geográfica, social e econômica, dificultando a visualização de variações internas importantes que poderiam ocorrer dentro de uma microrregião. $O$ fato de terem sido utilizados os dados do Universo limitou as possibilidades de aprofundamento em alguns itens pesquisados, tais como educação, por exemplo, limitado à alfabetização. A análise dos dados da amostra proporcionaria mais informações, tais como nível de ensino. Sugere-se em pesquisas futuras a possibilidade de análises que considerem o nível municipal e os dados da amostra do Censo Demográfico 2010.

Não foram consideradas, também, as diferenças inter-étnicas, sendo fator limitador das análises. Estudos posteriores deverão incluir o quesito de etnias indígenas em situação urbana, podendo traçar contornos ricos das diferenças socioeconômicas e demográficas existentes entre estas e mesmo possibilitando comparações com a situação dos não indígenas no estado do Amazonas. 
Espaço Ameríndio

\section{Referências bibliográficas}

AGOSTINI, C.A.; BROWN, P.H.; ROMAN, A. Poverty and Inequality Among Ethnic Groups in Chile. World Development. V.38, n. 7, p.1036-1046, 2010.

BOTELHO, J.B.; WEIGEL, V.A.C.M. Comunidade Sateré-Mawé Y'Apyrehyt: ritual e saúde na periferia urbana de Manaus. História, Ciências, Saúde - Manguinhos. v. 18, n. 3, p. 723-44, 2011.

COIMBRA Jr., C.E.A.; SANTOS, R.V. Saúde, minorias e desigualdade: algumas teias de inter-relações, com ênfase nos povos indígenas no Brasil. Ciência \& Saúde Coletiva. v.5, n.1, p.125-132, 2000.

CEPAL. Comisión Económica para América Latina y el Caribe. UN. United Nations. CELADE. Centro Latinoamericano y Caribeño de Demografía. Los pueblos indígenas em América Latina: Avances en el último decênio y retos pendientes para la garantía de sus derechos. Naciones Unidas, Santiago de Chile, 2014.

DEL POPOLO, F.; SCHKOLNIK, S. Pueblos indígenas y afrodescendientes en los censos de población y vivienda de América Latina: avances y desafíos en el derecho a la información. In: UN. United Nations. CEPAL. Comisión Económica para América Latina y el Caribe. CELADE. Centro Latinoamericano y Caribeño de Demografía. Notas de Población. Año XL, n.97, 2013.

FÍGOLI, L.H.G. Identidad Regional y "Caboclismo": Índios del Alto Rio Negro em Manaos. Anuário Antropológico. v. 83, p119-154, 1985.

FÍGOLI, L.H.G.; FAZITO, D. Redes sociales en una investigación de migración indígena: el caso de Manaus. Anais do XV Encontro Nacional de Estudos Populacionais, ABEP.p. 1-17, 22 out. 2006.

IBGE. Instituto Brasileiro de Geografia e Estatística. Tendências demográficas: uma análise dos indígenas com base nos resultados da amostra dos Censos Demográficos de 1991 e 2000. Rio de Janeiro, 2005.

IBGE. Instituto Brasileiro de Geografia e Estatística. Censo demográfico 2010. Características gerais dos indígenas: resultados do universo. Rio de Janeiro, 2012.

IBGE. Instituto Brasileiro de Geografia e Estatística. Censo demográfico 2010.Características urbanísticas do entorno dos domicílios. Rio de Janeiro, 2010a.

IBGE. Instituto Brasileiro de Geografia e Estatística. Diretoria de Pesquisas. Censo demográfico 2010. Modelo de investigação e conteúdo dos questionários do Censo Demográfico 2010. Rio de Janeiro, 2010b.

IBGE. Instituto Brasileiro de Geografia e Estatística. Censo demográfico 2010. Características da população e dos domicílios: resultados do universo. Rio de Janeiro, 2011. 
IBGE. Instituto Brasileiro de Geografia e Estatística. Censo Demográfico 2010. Metodologia do Censo Demográfico 2010. Série Relatórios Metodológicos. Volume 41. Rio de Janeiro, 2013.

ISA. Instituto Socioambiental. Povos Indígenas no Brasil. Terras indígenas no Brasil. Localização e extensão das TIs. 2015. Acesso em: 24/03/2016. Disponível em: $<$ http://pib.socioambiental.org/pt/c/terras-indigenas/demarcacoes/localizacao-eextensao-das-tis $>$

KING, M.; SMITH, A.; GRACEY, M. Indigenous health part 2: the underlying causes of the health gap. Lancet. V.374, p.76-85, 2009.

MAINBOURG, E.T.; ARAÚJO, M.I.; ALMEIDA, I.C. Populações Indígenas da cidade de Manaus: inserção na cidade e ligação com a cultura. Anais do XIII Encontro da Associação Brasileira de Estudos Populacionais, ABEP. p. 1-13 , 8 nov. 2002.

MAINBOURG, E.T.; ARAÚJO, M. I.; ALMEIDA, I. C. Condições domiciliares e peridomiciliares em Manaus, Amazonas: comparação entre indígenas segundo a etnia e não indígenas. Anais do XV Encontro Nacional de Estudos Populacionais, ABEP. p. 110,22 out. 2006.

MAINBOURG, E.T. ARAÚJO, M.I.; ALMEIDA, I.C. Condutas/condições de Saúde em Manaus, Amazonas: comparação entre indígenas e não indígenas. Anais Do XVI Encontro Nacional de Estudos Populacionais, ABEP. Outubro 3, 2008, p. 1-10.

MITROU, F.; COOKE, M.; LAWRENCE, D. et al. Gaps in Indigenous disadvantage not closing: a census cohort study of social determinants of health in Australia, Canada, and New Zealand from 1981-2006. BMC Public Health. 2014 v.14, n.201, 2014.

PAGLIARO, H.; AZEVEDO, M.M.; SANTOS, R.V. Demografia dos Povos Indígenas no Brasil: um panorama crítico. In: PAGLIARO, H.; AZEVEDO, M.M.; ANTOS, R.V. (Orgs.). Demografia dos povos indígenas no Brasil. Rio de Janeiro: Editora FIOCRUZ, 2005.

SANTOS, R.V.; TEIXEIRA, P. O "indígena" que emerge do Censo Demográfico de 2010. Editorial. Cad. Saúde Pública. v.27, n.6, p.1048-1049, 2011.

SANTOS, R.V. PEREIRA, N.O.M. Indigenous peoples in the Brazilian national censos. Editorial. Cad. Saúde Pública. V.21, n.6, p.1626-1627, 2005.

TEIXEIRA, P. Sateré-Mawé: retrato de um povo indígena. UFAM/UNICEF: Manaus, abril de 2005.

TEIXEIRA, P.; MAINBOURG, E.M.T.; BRASIL, M. Migração do povo indígena SateréMawé em dois contextos urbanos distintos na Amazônia. Caderno CRH. v.22, n.57, 2009. 
Recebido em: 20/01/2020 * Aprovado em: 24/09/2020 * Publicado em: 16/12/2020 